\title{
Materials Evaluation and Monitoring of a Large-Scale Conservation Project: Eight Monumental Bronze Sculptures by A.M. Calder
}

Andrew Lins

Conservation Department, Philadelphia Museum of Art, PO Box 7646, Philadelphia PA 19101

Among the challenges facing historic preservation in America today is the need to establish that conservation efforts utilize currently available technology to create the best possible, longest lasting and most cost-effective results feasible, justifying the labor and investment which preservation efforts require. This paper describes the preliminary evaluation and in-process, on site monitoring involved in a large-scale project to repair and stabilize eight monumental bronze sculptures situated on the massive clock tower of Philadelphia City Hall, some 350 feet above ground level with very limited access. Created by A. M. Calder and installed between 1894 and 1896, the sculptures comprise four figural groups (each averaging 16-18 feet high and weighing 14,000 lbs) and four eagles (each with a wingspan 12 feet and weighing 7,000 lbs). The sculptures were comprised of sand-cast, flanged sections that were bolted together with ferrous fasteners. Beyond the structural necessity of replacing the ferrous fasteners with 2200 silicon or stainless steel fasteners, the two basic questions for the eight sculptures in this conservation program were:

- What were the safest, lowest risk, affordable cleaning and coating procedures that could be applied with predictable longevity exceeding ten years?

- How easily could the sculptures be maintained to create the longest interval between retreatment, thereby reducing long-term costs to the City for preservation?

The above questions and related material analyses were addressed in work undertaken at the Philadelphia Museum of Art from 2003-2007 for the City of Philadelphia. In particular the surface cleaning rates and completeness of corrosion removal attainable with innovative laser ablation technology was compared against uhp water using SEM-EDS and WDS, FTIR, and XRD techniques and traditional metallography. Candidates for maintenance coatings were evaluated.

In 2004-5, initial analyses indicated that the NdYAG lasers first tested by Conservation of Sculpture and Objects Studio of Chicago (CSOS) were able to clean the active green-blue and red copper corrosion areas (primarily sulfates, chlorides and oxides) with reasonable efficiency but were less successful in removing the black accretions (composed variously of carbonaceous, silicaceous and calcareous particulates) and at a very reduced rate compared to the green-blue corrosion. In SEM images at magnifications above 500X, the laser-cleaned surfaces often showed "micromelting" and microcratering features, leading to tunneling and spheroidal features, typically confined to the first 10-15 micrometers of the weathered surfaces. Metallographic sections were prepared to document the depth of alterations before and after lasering. In spite of the demonstrated slowness of the laser cleaning compared to uhp water, the laser-based proposal from CSOS was selected by the City of Philadelphia on the basis of cost and of assessed risk The staging, containment and clean-up issues were better answered by the laser cleaning than UHPW, as the former required only light and a HEPA vacuum for the cleaning, etc. The City risk assessors concluded that the uhp water proposals posed numerous mechanical and plumbing hazards, with the potential of water damage - a repeated problem in City Hall - too critical to be approved.

As work progressed on site in 2005, the susceptibility of newly lasered surfaces to recorrode also was followed in a series of tests over the course of a month. These tests indicated that many black areas harbored antlerite and chloride-rich species that became active corrosion sites after lasering. This finding resulted in a more controlled laser dwell time on those black areas and improved rinsing and patination procedures to eliminate chlorides, the principal cause of premature coating failure in similar projects. Of concern during this analytical work was the occasional 
finding that arsenic was among the very minor constituents/impurity in the bronze alloys. Together with the lead component more commonly detected, these elements represented hazards produced in the laser plume, for which CSOS staff were required to employ appropriate vacuum trapping and ventilation.

Coincident with the massive, though short-lived energy absorption that created the gas byproducts, there was a selective loss of low melting point components of the various bronze alloys of the castings, in particular the tin-rich delta phase, the separate lead phase, and zinc from the alpha phase. In effect, the laser interaction appeared to have created a copper-enriched surface with fewer elemental inhomogeneities than were present in the original alloy, producing more uniform and more reliable substrates on which to build a stable mineral layer of patination and protective coating. Also observed during these analyses was the "shadowing" of the beam when it encountered non-vertical porosities or flaws in the surface; i.e., the beam could not ablate corrosion from surface pits if those pits ran at an angle to the surface, instead of straight down from the surface. All aspects of the finish procedures (steaming/rinsing, patination, inhibitor application, and coating) also were evaluated and monitored during the project, providing direct, real-time feedback with the goal of substantially improving quality control and the performance/ longevity of the treatment. A positive byproduct of the project has been research on a fluorocarbon coating to extend the lifetime of the restoration, with potential benefit to the conservation field.
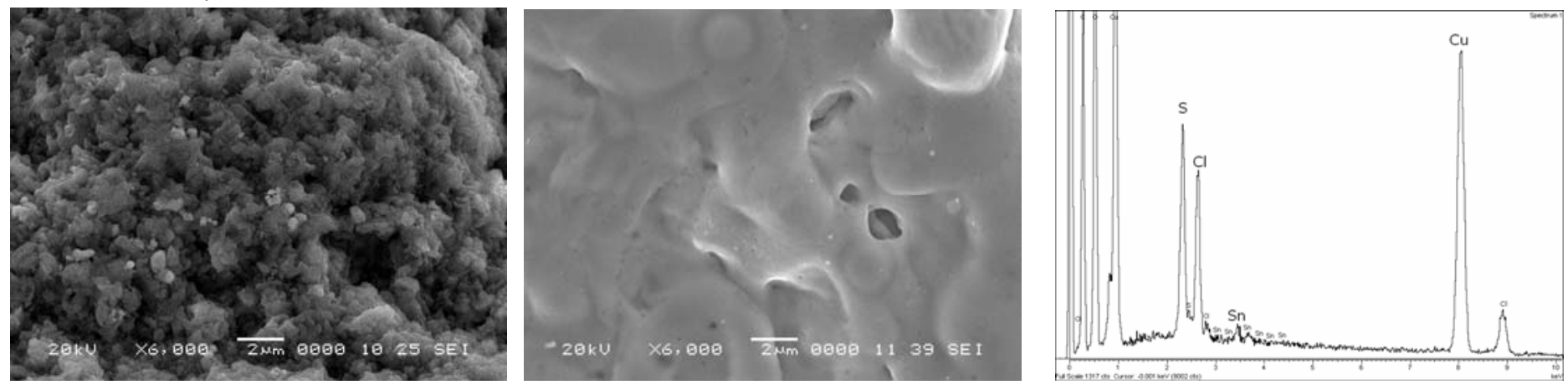

Image at $6000 \mathrm{X}$ of weathered surface. Image at $6000 \mathrm{X}$ after laser cleaning.

Representative EDS spectrum of a scraped surface reaction product after cleaning.

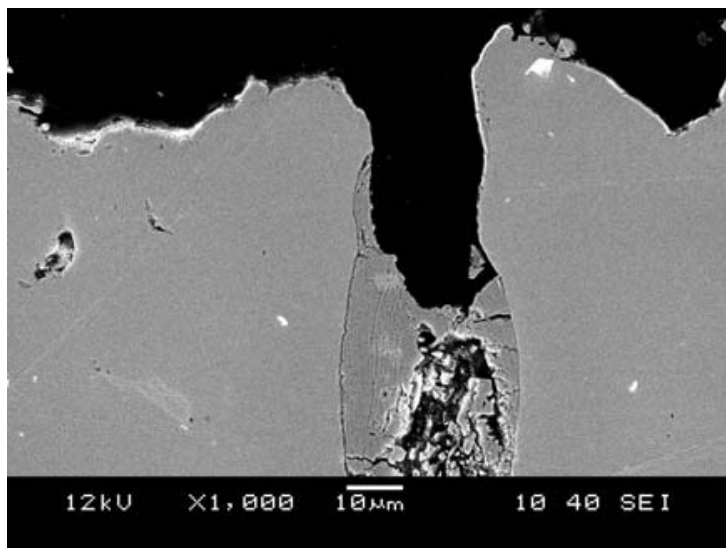

1000X SEM image of deep surface pit after laser cleaning. The laser cleaned the upper $40 \mu \mathrm{m}$; below corrosion remains

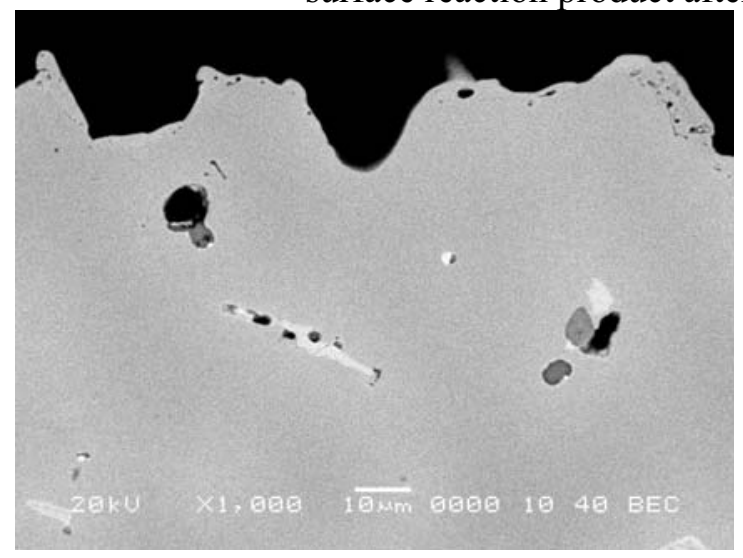

1000X SEM laser cleaned surface. Image shows spherical porosities at the metal/air interface, due to generation of gas during ablation..

\section{References:}

A. Dajnowski, A.Jenkins and A.Lins, APT Bulletin XL (2009) no 1, 13-24.

T.L. Clare and A. Lins, Metals '07: Proc.of the Int. Conf. on Metals Conservation, Amsterdam

A. Dajnowski and A.Lins LACONA VIII (2009), Sibiu, Romania, in press.

A. Lins, Dialogue '89, NACE:Houston Texas, 1992 